\title{
Claudie Bernard, Le Jeu des familles dans le roman du $\mathrm{XIX}$ siècle
}

\section{Maria Emanuela Raffi}

\section{(2) OpenEdition}

\section{Journals}

\section{Edizione digitale}

URL: http://journals.openedition.org/studifrancesi/1577

DOI: 10.4000/studifrancesi. 1577

ISSN: 2421-5856

\section{Editore}

Rosenberg \& Sellier

\section{Edizione cartacea}

Data di pubblicazione: 1 novembre 2014

Paginazione: 623

ISSN: 0039-2944

\section{Notizia bibliografica digitale}

Maria Emanuela Raffi, «Claudie Bernard, Le Jeu des familles dans le roman du xix siècle », Studi Francesi [Online], 174 (LVIII | III) | 2014, online dal 01 novembre 2014, consultato il 18 septembre 2020. URL : http://journals.openedition.org/studifrancesi/1577 ; DOI : https://doi.org/10.4000/studifrancesi.1577

Questo documento è stato generato automaticamente il 18 settembre 2020.

\section{@(๑) $\Theta \Theta$}

Studi Francesi è distribuita con Licenza Creative Commons Attribuzione - Non commerciale - Non opere derivate 4.0 Internazionale. 


\title{
Claudie Bernard, Le Jeu des familles dans le roman $\mathrm{du} X \mathrm{XI}^{\mathrm{e}}$ siècle
}

\author{
Maria Emanuela Raffi
}

\section{NOTIZIA}

CLAUDIE BERNARD, Le Jeu des familles dans le roman du XIXe siècle, Publications de l'Université de Saint-Étienne, 2013, pp. 323.

1 «Le jeu des sept familles», gioco infantile che ha avuto origine nell'Ottocento e la cui logica consiste nella ricomposizione delle famiglie di carte distribuite in modo accidentale fra i giocatori, funge da punto di partenza per la riflessione di Claudie Bernard sulle famiglie e le loro dinamiche nella rappresentazione narrativa di alcuni importanti autori del xIX secolo, raggruppati in quattro unità tematiche fondamentali, spesso a cavallo delle due metà del secolo.

2 In «Nostalgies patriarchales» troviamo anzitutto l'osservazione della famiglia come «véritable élément social» operata da Balzac, attraverso lo sguardo carico di rimpianto per la struttura familiare gerarchica prerivoluzionaria che appare in Mémoires de deux jeunes mariées. È poi L'Étape di Bourget ad essere preso in considerazione dalla Bernard, anch'esso espressione di un pensiero cattolico e monarchico che stigmatizza la decadenza della famiglia, dovuta allo sradicamento dell'individuo, all'abuso del pensiero razionale, al rifiuto della fede e della tradizione.

3 «Malentendus paternalistes», seconda parte, chiama in causa di nuovo Balzac e particolarmente Ursule Mirouët, romanzo in cui è indagata la famiglia borghese, caratterizzata non più dalla gerarchia ma dalla «circulation» - di sangue, di denaro, di persone - e i cui elementi strutturanti sono l'eredità e i legami di matrimonio. «Le jeu des familles bourgeoises» appare appieno, per la Bernard, in Renée Mauperin, dove $\mathrm{i}$ Goncourt illustrano ampiamente la rivoluzione sociale avvenuta dal 1789 alla Monarchia di luglio: «détrônement concomitant des patriarchies royales et du patriarcat domestique, et [...] débordement de la revendication individualiste dans des 
catégories jusque-là subordonnées, plébéiens dans l'État, femmes et mineurs au foyer». Le Docteur Pascal di Zola è l'oggetto dell'analisi successiva; il tentativo del suo protagonista di correggere, alla fine dei Rougon-Macquart, la legge dell'ereditarietà attraverso il suo triplice ruolo di medico, patologo e genetista mette in luce, secondo la Bernard, i due principi cardinali di tutta la creazione zoliana: l'imitation, «reproduction des êtres sous l'empire du semblable» e l'invention, «reproduction des êtres sous l'empire du divers».

4 Nella terza parte, «Rédemptions fraternitaires», Claudie Bernard analizza il concetto di fraternité (repubblicana e cristiana) nel romanzo di Georges Sand Le Compagnon du Tour de France, scritto in un periodo di particolare attenzione sociale per l'associazionismo e «le compagnonnage», che si sovrappone in larga misura anche alla struttura famigliare. Le Juif errant de Sue sembra offrire una diversa prospettiva sull'associazionismo, applicato qui al tentativo di ricongiungere una famiglia dispersa, di ricostituire la maisonnée, che viene ad assumere però un significato molto più ampio di «entité de production et de consommation économique, mais aussi sexuelle». Accanto a questo, Sue presenta, come rileva la Bernard, anche un altro esempio di associazionismo fraternitario «la confrérie jésuite», che suscita la critica veemente dell'autore.

«Déviances et décadences», ultima parte, inizia con l'analisi di Les Frères Zamganno, romanzo che Edmond de Goncourt consacra alla «relation adelphique». Benché la coppia di fratelli protagonisti della narrazione sia lontanissima dai Goncourt, la figura del fratello maggiore, che cumula le funzioni di padre e madre, il legame fortissimo e creativo che li lega nell'elaborazione di un numero acrobatico - «mise en abyme d'un désir inavouable» - e soprattutto la morte del fratello più giovane riconducono, per la Bernard, al latente senso di colpa di Edmond per la morte di Jules, che traspare chiaramente nel Journal: «Peut-être, sans moi, se serait-il fait peintre. Doué comme il l'était, il aurait fait son nom sans s'arracher la cervelle... et il vivrait». Ciò che caratterizza il romanzo Une histoire sans nom di Barbey d'Aurevilly, sempre dal punto di vista del tema famigliare trattato dalla Bernard, è invece la centralità del nome, legata alla paternità illegittima del monaco Riculf, ma anche al nome della famiglia infangato dalla maternità di Lasthénie. I legami parentali assicurano qui soprattutto che le colpe dei genitori ricadano sui figli e che tutti condividano la punizione di Dio, padre geloso e vendicativo. Le Crépuscule des dieux di Élémir Bourges, ultimo romanzo considerato da Claudie Bernard, mostra il punto d'arrivo del decadimento, mettendo in scena una famiglia-dinastia nel momento della sua decomposizione, causata dal "parasitage» parentale, dalle «mésalliances» e dall'autodistruzione dei membri della famiglia (malattie, incesto, decadenza economica), sullo sfondo costante della musica wagneriana. 